\title{
SUBCLINICAL HYPOTHYROIDISM IN TYPE 2 DIABETES MELLITUS: PREVALENCE AND EFFECTS ON GLYCAEMIC AND LIPID PROFILE
}

\author{
Sivaram Kannan S $^{1}$ Damodaran Dhanasekaran ${ }^{2}$
}

${ }^{1}$ Assistant Professor, Department of Internal Medicine, Madras Medical College, Chennai.

${ }^{2}$ Assistant Professor, Department of Internal Medicine, Madras Medical College, Chennai.

\section{ABSTRACT}

\section{BACKGROUND}

There is a significant prevalence of thyroid disorders in patients with diabetes mellitus, the most common being subclinical hypothyroidism. The coexistence of subclinical hypothyroidism in diabetes may alter the glycaemic profile and lipid profile that is expected in these patients

Objectives- To determine the prevalence of subclinical hypothyroidism in patients with type 2 diabetes mellitus and to evaluate glycaemic profile and lipid profile in patients having both the disorders.

\section{MATERIALS AND METHODS}

The study was done at a tertiary care hospital (Rajiv Gandhi Government General Hospital attached to Madras Medical College in the Institute of Internal Medicine). A total of 245 patients were screened during the study period between June 2016 to December 2016 and 200 patients above 40 years diagnosed to have type 2 diabetes mellitus without any previous history of thyroid dysfunction were subjected to a short relevant history and physical examination as per a set questionnaire. Liver and renal function tests, fasting thyroid profile and fasting lipid profile were taken for all patients. Those who had abnormal liver/renal function test were excluded (45 patients were excluded). The following investigations were performed for all patients: Fasting blood sugar (FBS), Haemoglobin $\mathrm{A}_{1 \mathrm{c}}\left(\mathrm{HbA}_{1 \mathrm{c}}\right.$ ), Serum free $\mathrm{T}_{3}$, free $\mathrm{T}_{4}$ and thyroid stimulating hormone (TSH), complete fasting lipid profile, electrocardiogram (ECG), 2D Echocardiography, ophthalmological evaluation, urine routine, blood urea, serum creatinine, liver function tests, and serum electrolytes.

\section{RESULTS \\ Hypothyroidism was present in $12 \%$ of cases. Prevalence was significantly higher in females (13.9\%) than males (9.8\%), but not statistically significant when Chi-squared test was applied ( $p$ value 0.57). The presence of subclinical hypothyroidism was significantly related to higher levels of $\mathrm{HbA}_{1 \mathrm{c}}$. The mean $\mathrm{HbA}_{1 \mathrm{c}}$ in the groups with and without subclinical hypothyroidism was $8.53 \%$ and $7.93 \%$ respectively. There was no significant correlation between duration of diabetes and presence of subclinical hypothyroidism. There was a higher but insignificant prevalence of total and LDL cholesterol, and there was no significant increase in prevalence of low HDL cholesterol in patients with subclinical hypothyroidism. There was a significantly higher prevalence of hypertriglyceridaemia (64.3\% versus $18.5 \%$ ) and the mean value of serum triglyceride level was $184.4 \mathrm{mg} / \mathrm{dL}$ in patients with subclinical hypothyroidism versus $151.3 \mathrm{mg} / \mathrm{dL}$ among those with only diabetes.}

\section{CONCLUSION}

There is a significant increase in the incidence of subclinical hypothyroidism in patients with type 2 diabetes mellitus, and this increase is associated with a significant rise in triglyceride levels and $\mathrm{HbA}_{1 \mathrm{c}}$ levels. There is no correlation between total cholesterol, and LDL and HDL cholesterol with presence of subclinical hypothyroidism.

\section{KEYWORDS}

Subclinical Hypothyroidism, Type 2 Diabetes Mellitus, Lipid Profile, $\mathrm{HbA}_{1 \mathrm{c}}$.

HOW TO CITE THIS ARTICLE: Kannan SS, Dhanasekaran D, Subclinical hypothyroidism in type 2 diabetes mellitus: Prevalence and effects on glycaemic and lipid profile. J. Evolution Med. Dent. Sci. 2017;6(46):3586-3589, DOI: 10.14260/Jemds/2017/773

\section{BACKGROUND}

Two of the most common endocrinological diseases are diabetes mellitus (DM) and hypothyroidism. Hypothyroidism may be subclinical or overt. Subclinical hypothyroidism (SCH) is diagnosed in the presence of an elevated serum TSH with a normal serum free $\mathrm{T}_{4}$ whereas overt hypothyroidism is diagnosed when there is an elevated serum TSH with

Financial or Other, Competing Interest: None.

Submission 13-03-2017, Peer Review 27-05-2017,

Acceptance 02-06-2017, Published 08-06-2017.

Corresponding Author:

Dr. Damodaran Dhanasekaran,

No. 6 A, Adhilakshmi Nagar,

Lakshmipuram, Chennai-600099.

E-mail: dhamodharan.d@gmail.com

DOI: $10.14260 /$ jemds $/ 2017 / 773$

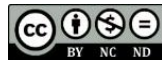

decreased free $\mathrm{T}_{4}$. Subclinical hypothyroidism may be found in $6.1 \%$ women and $3.4 \%$ men.[1] The annual risk of developing overt hypothyroidism is about $4 \%$ when there is an associated positive TPO antibody.[2] There is a significant proportion of individuals who suffer from thyroid dysfunction in the diabetic population, the most frequent pattern being $\mathrm{SCH}$, and these thyroid disorders are more prevalent in women than in men. ${ }^{[3]}$

Both hypothyroidism and diabetes alter lipid levels and are the leading causes of dyslipidaemia in the current era. However, the pattern of altered lipid profile varies in the two diseases. Whereas diabetes causes abnormalities primarily in high density lipoprotein (HDL) fraction of serum cholesterol, hypothyroidism primarily affects the low density lipoprotein (LDL) cholesterol.[4,5] Both disorders can cause an elevation in the serum triglyceride level. It is important to realise these 
altered lipid profiles in the above two diseases as they pose a significant risk for atherosclerotic progression and adverse cardiac and vascular outcomes in an individual. However, the lipid profile pattern in patients suffering from both diabetes and subclinical hypothyroidism has not been studied extensively and remains controversial.

One of the major metabolic pathways that is primarily affected in thyroid dysfunction is that of glucose. Thyroid hormones regulate glucose absorption from the gut, and there is a documented reduction in absorption in hypothyroid patients, therefore one expects a decreased glucose level in these patients. But this is not so. There are many factors that increase the glucose levels in hypothyroid individuals as well. These include an increased peripheral resistance to insulin due to an increase in adipose tissue mass, a decreased expression of glucose receptors in the peripheral tissues, and many more, including altered gene expression for insulin hormone. Hence, the glycaemic control in diabetics with hypothyroidism (overt and subclinical) may not be good despite strict dietary and lifestyle modifications, and there are conflicting reports regarding this observation. The consequences of hypothyroidism are many, majority of them having an effect over the cardiac and vascular system, and many complications overlap with the microvascular and macrovascular complications of diabetes. It also becomes a significant comorbid condition that hampers the proper management of diabetes, posing to be a burden for the patient and the doctor. It is therefore, very important to screen for and detect type 2 diabetes mellitus patients who have a coexisting subclinical hypothyroidism and treat them accordingly.

\section{Objectives}

1. To determine the prevalence of $\mathrm{SCH}$ in patients with type 2 DM.

2. To study the effects of SCH on glycaemic profile and lipid profile in patients with type $2 \mathrm{DM}$.

\section{MATERIALS AND METHODS}

This study was conducted at the Institute of Internal Medicine, Rajiv Gandhi Government General Hospital, Chennai. This is an observational study. Two hundred individuals aged above 40 years with a history of type 2 DM were included in the study. Patients not willing to give consent, those with a history of thyroid disease, patients with biochemical and clinical features of hyperthyroidism, patients with critical illnesses, and patients with abnormal liver or renal function were excluded from the study. An informed written consent was taken from all patients and the study was approved by the institutional ethics committee. A short relevant history, physical examination and necessary laboratory investigations were performed as per a set questionnaire designed for the study.

Fasting blood sugar (FBS), haemoglobin $\mathrm{A}_{1 \mathrm{c}}\left(\mathrm{HbA}_{1 \mathrm{c}}\right)$, serum free $T_{3}$, free $T_{4}$ and thyroid stimulating hormone (TSH), complete fasting lipid profile, electrocardiogram (ECG), 2D Echocardiography, ophthalmological evaluation, urine routine, blood urea, serum creatinine, liver function tests, and serum electrolytes were performed to all patients after applying the exclusion criteria. All analyses were conducted using the Statistical Package for the Social Sciences (SPSS) 16 software.
Hypothyroidism was defined as a serum TSH $>5.5$ $\mu \mathrm{IU} / \mathrm{mL}$ with serum free $\mathrm{T}_{4}<1.8 \mathrm{ng} / \mathrm{dL}$ with or without clinical features of hypothyroidism. Normal values: $\mathrm{HbA}_{1 \mathrm{c}}$ $<6.5 \%$, total cholesterol $<200 \mathrm{mg} / \mathrm{dL}$, serum HDL $>40 \mathrm{mg} / \mathrm{dL}$, serum $\mathrm{LDL}<100 \mathrm{mg} / \mathrm{dL}$, and triglycerides $<150 \mathrm{mg} / \mathrm{dL}$.

\section{Statistical Analysis}

Statistics were presented as mean \pm standard deviation for continuous measures while absolute values and percentages for categorical measures. All analyses were conducted using the Statistical Package for the Social Sciences (SPSS) 16 statistical software (SPSS Inc., Chicago, Illinois, USA). A P $<0.05$ was considered to be statistically significant.

\section{RESULTS}

In the current study, out of 200 individuals, 168 patients had normal thyroid function. This accounted for $86 \%$ of the cases. Twenty-four individuals (12\% of cases) had a biochemical diagnosis of SCH. Eight patients had overt hypothyroidism (OHT), defined as an elevated TSH level along with a suppressed free $\mathrm{T}_{4}$ level. The study showed a statistically significant prevalence of subclinical hypothyroidism in patients with type 2 diabetes ( $\mathrm{p}$ value $=0.025$ ).

The average age of diabetic individuals with an abnormal thyroid function was 65.4 years, compared to 67.12 years in type $2 \mathrm{DM}$ with a normal thyroid function.

The participants of the study were divided based on the gender and it was observed that 92 individuals out of 200 were male (46\%), and 108 out of 200 were female (54\%). Among the male population, 80 individuals (87\% males) had normal thyroid function, 9 had SCH $(9.8 \%)$ and 3 had OHT (3.3\%). Among the females, 88 individuals (81.5\% females) had normal thyroid function, 15 had SCH (13.9\%) and 5 had OHT (4.6\%). Among patients with SCH, 9 patients were male, accounting to $37.5 \%$ individuals. The rest 15 out of 24 patients were female, making up $62.5 \%$. The prevalence of SCH in patients with type $2 \mathrm{DM}$ is higher in females, but not statistically significant (p-value 0.5747 ). [Table 1].

Individuals were grouped according to Glycated haemoglobin levels $\left(\mathrm{HbA}_{1 \mathrm{c}}\right.$ ) into $\mathrm{HbA}_{1 \mathrm{c}}<7 \%, \mathrm{HbA}_{1 c} 7$ to $10 \%$, and $\mathrm{HbA}_{1 \mathrm{c}}>10 \%$, and normal and abnormal TSH values into $0.3-5.5$, and $>5.5 \mu \mathrm{IU} / \mathrm{mL}$. Out of 168 individuals who with a normal TSH value, $56(33.3 \%)$ had $\mathrm{HbA}_{1 \mathrm{c}}<7 \%$ and 94 (56\%) had $\mathrm{HbA}_{1 \mathrm{c}}$ between $7-10 \%$. Only 18 out of 168 individuals (10.7\%) had $\mathrm{HbA}_{1 \mathrm{c}}$ levels more than $10 \%$ and yet had a normal thyroid function test. Among individuals with increased TSH values, $40.63 \%$ of them had $\mathrm{HbA}_{1 \mathrm{c}}$ more than $10 \%$. The mean $\mathrm{HbA}_{1 \mathrm{c}}$ value in diabetic individuals without thyroid abnormalities was $7.93 \%$. The mean $\mathrm{HbA}_{1 \mathrm{c}}$ value in individuals with type $2 \mathrm{DM}$ and $\mathrm{SCH}$ was $8.53 \%$. The average $\mathrm{HbA}_{1 \mathrm{c}}$ in individuals with an abnormal thyroid function was $8.31 \%$, a value higher than those with normal thyroid function [Table 2].

\section{Lipid Profile in Subclinical Hypothyroidism}

The upper limit of normal of serum total cholesterol was taken as $200 \mathrm{mg} / \mathrm{dL}$ as per the standards in the biochemistry department. Based on this, participants were separated into two groups - one with a normal $(<200 \mathrm{mg} / \mathrm{dL})$ and elevated $(>200 \mathrm{mg} / \mathrm{dL})$ total cholesterol. In patients with Type $2 \mathrm{DM}$ and normal thyroid function, 30.4\% (51 out of 168) had elevated total cholesterol, whereas in patients with $\mathrm{SCH}$, $45.9 \%$ (11 out of 24 ) had an abnormal total cholesterol. The 
mean values of total cholesterol in the euthyroid group and the SCH group were $181.9 \mathrm{mg} / \mathrm{dL}$ and $189.17 \mathrm{mg} / \mathrm{dL}$ respectively. Although the percentage of individuals with a higher cholesterol level was more in the SCHT group, the correlation was statistically not significant. [Table 3].

The upper limit of normal of serum LDL cholesterol as per the standards in department of Biochemistry was taken as $100 \mathrm{mg} / \mathrm{dL}$. Participants were grouped into those having normal and elevated serum LDL cholesterol levels $(<100$ $\mathrm{mg} / \mathrm{dL}$ and $>100 \mathrm{mg} / \mathrm{dL}$ respectively). The total number of participants with elevated serum LDL cholesterol was 105 out of 200. Fifty three percent of individuals with normal thyroid function (89 out of 168) had elevated LDL cholesterol, versus $66.7 \%$ in patients with SCH (16 out of 24). The mean LDL cholesterol values were $108.39 \mathrm{mg} / \mathrm{dL}$, and $121.15 \mathrm{mg} / \mathrm{dL}$ in normal thyroid, and $\mathrm{SCH}$ groups respectively. [Table 4].

The normal limits of HDL cholesterol was taken to be more than $40 \mathrm{mg} / \mathrm{dL}$. Participants were grouped into those with low and normal HDL cholesterol levels $(<40$ and $>40$ $\mathrm{mg} / \mathrm{dL}$ respectively). The prevalence of patients with a low HDL cholesterol was $39.3 \%$ in normal thyroid status group (66 out of 168), and 50\% in SCH group (12 out of 24). This showed a rising trend in the prevalence of abnormal HDL cholesterol levels from normal to subclinical hypothyroid cases. However, this trend was shown to be statistically insignificant. The mean values of HDL cholesterol were 42.44, and $42.45 \mathrm{mg} / \mathrm{dL}$ in normal thyroid individual and individuals with SCH respectively. [Table 5].

The normal value of serum triglyceride levels was taken to be below $150 \mathrm{mg} / \mathrm{dL}$ as per standard laboratory definitions. Among individuals with type $2 \mathrm{DM}$ and normal thyroid status, 145 of them (81.5\%) had serum triglyceride levels less than $150 \mathrm{mg} / \mathrm{dL}$, and $33(18.5 \%)$ had an increased triglyceride level more than $150 \mathrm{mg} / \mathrm{dL}$. Among those with SCH, 5 patients had levels $<150 \mathrm{mg} / \mathrm{dL}$ (35.7\%) and 9 members $(64.3 \%)$ had elevated levels of triglycerides $>150$ $\mathrm{mg} / \mathrm{dL}$. The observation that elevated levels of triglycerides are seen in the group with $\mathrm{SCH}$ was statistically relevant ( $\mathrm{p}$ value 0.0001415 ). The mean values of serum triglyceride levels were 151.3 , and $184.4 \mathrm{mg} / \mathrm{dL}$ in euthyroid and SCH patients respectively [Table 6].

\begin{tabular}{|c|c|c|c|}
\hline & Male (\%) & Female (\%) & Total (\%) \\
\hline Euthyroid & $80(87)$ & $88(81.5)$ & $168(84)$ \\
\hline SCH & $9(9.8)$ & $15(13.9)$ & $24(12)$ \\
\hline OHT & $3(3.3)$ & $5(4.6)$ & $8(4)$ \\
\hline Total & $\mathbf{9 2}$ & $\mathbf{1 0 8}$ & $\mathbf{2 0 0}$ \\
\hline $\begin{array}{c}\text { Table 1. Gender Distribution of Subclinical and Overt } \\
\text { Hypothyroidism among Individuals included in the Study }\end{array}$ \\
\hline
\end{tabular}

p value 0.5747

\begin{tabular}{|c|c|c|c|}
\hline TSH $(\boldsymbol{\mu I U} / \mathbf{m L})$ & $\mathbf{0 . 3}-\mathbf{5 . 5}(\%)$ & $>\mathbf{5 . 5}(\%)$ & Total \\
\hline $\mathrm{HbA}_{1 \mathrm{c}}<7 \%$ & $56(33.3)$ & $3(9.4)$ & $59(29.5)$ \\
\hline $\mathrm{Hb}_{1 \mathrm{c}} 7-10 \%$ & $94(56)$ & $16(50)$ & $110(55)$ \\
\hline $\mathrm{HbA}_{1 \mathrm{c}}>10 \%$ & $18(10.7)$ & $13(40.6)$ & $31(15.5)$ \\
\hline Total & $\mathbf{1 6 8}$ & $\mathbf{3 2}$ & $\mathbf{2 0 0}$ \\
\hline \multicolumn{4}{|c|}{ Table 2. Relationship between $\mathbf{H b A}_{1 c}$ and TSH } \\
Levels among Individuals Included in the Study \\
\hline
\end{tabular}

Yates p value 0.00011

\begin{tabular}{|c|c|c|c|c|}
\hline $\begin{array}{c}\text { Total Cholesterol } \\
\text { (mg/dL) }\end{array}$ & $\begin{array}{c}\text { Normal } \\
(\mathbf{\% )})\end{array}$ & $\begin{array}{c}\text { SCH } \\
\text { (\%) }\end{array}$ & $\begin{array}{c}\text { OHT } \\
\text { (\%) }\end{array}$ & Total \\
\hline$<200$ & $117(69.6)$ & $13(54.1)$ & $5(62.5)$ & 135 \\
\hline$>200$ & $51(30.4)$ & $11(45.9)$ & $3(37.5)$ & 65 \\
\hline Total & $\mathbf{1 6 8}$ & $\mathbf{2 4}$ & $\mathbf{8}$ & $\mathbf{2 0 0}$ \\
\hline \multicolumn{4}{|c|}{ Table 3. Prevalence of Hypercholesterolaemia } \\
in Individuals with and without \\
Hypothyroidism (Subclinical and Overt)
\end{tabular}

Yates' p-value 0.438

\begin{tabular}{|c|c|c|c|c|}
\hline $\begin{array}{c}\text { LDL Cholesterol } \\
\text { (mg/dL) }\end{array}$ & $\begin{array}{c}\text { Normal } \\
(\%)\end{array}$ & $\begin{array}{c}\text { SCH } \\
(\%)\end{array}$ & $\begin{array}{c}\text { OHT } \\
(\%)\end{array}$ & Total \\
\hline$<100$ & $79(47)$ & $8(33.3)$ & $5(62.5)$ & 95 \\
\hline$>100$ & $89(53)$ & $16(66.7)$ & $3(37.5)$ & 105 \\
\hline Total & $\mathbf{1 6 8}$ & $\mathbf{2 4}$ & $\mathbf{8}$ & $\mathbf{2 0 0}$ \\
\hline Table 4. Prevalence of Elevated LDL Cholesterol in \\
Individuals with and without Hypothyroidism \\
(Subclinical and Overt)
\end{tabular}

Yates' p-value 0.4829

\begin{tabular}{|c|c|c|c|c|}
\hline $\begin{array}{c}\text { HDL } \\
\text { Cholesterol } \\
\text { (mg/dL) }\end{array}$ & $\begin{array}{c}\text { Normal } \\
\text { (\%) }\end{array}$ & SCH (\%) & OHT (\%) & Total \\
\hline$>40$ & $102(60.7)$ & $12(50)$ & $3(37.5)$ & 117 \\
\hline$<40$ & $66(39.3)$ & $12(50)$ & $5(62.5)$ & 83 \\
\hline Total & $\mathbf{1 6 8}$ & $\mathbf{2 4}$ & $\mathbf{8}$ & $\mathbf{2 0 0}$ \\
\hline $\begin{array}{c}\text { Table 5. Prevalence of Decreased HDL Cholesterol } \\
\text { in Individuals with and without Hypothyroidism } \\
\text { (Subclinical and Overt) }\end{array}$ \\
\hline
\end{tabular}

Yates' p-value 0.5021

\begin{tabular}{|c|c|c|c|c|}
\hline $\begin{array}{c}\text { Serum } \\
\text { Triglycerides } \\
\text { (mg/dL) }\end{array}$ & Normal (\%) & SCH (\%) & OHT (\%) & Total \\
\hline$<150$ & $145(81.5)$ & $5(35.7)$ & $3(37.5)$ & 153 \\
\hline$>150$ & $33(18.5)$ & $9(64.3)$ & $5(62.5)$ & 47 \\
\hline Total & 178 & 14 & 8 & 200 \\
\hline
\end{tabular}

Table 6. Prevalence of Hypertriglyceridaemia in Individuals

with and without Hypothyroidism (Subclinical and Overt) Yates' p-value 0.0001415

\section{DISCUSSION}

Subclinical hypothyroidism is a common disorder, yet frequently underdiagnosed in the general population. The diagnosis is based on biochemical findings rather than clinical, defined by an elevated serum TSH with a normal serum free $\mathrm{T}_{4}$ level, regardless of the presence or absence of clinical features of hypothyroidism. In studies based on the general population, the range of prevalence of SCH is from 3 to $16 \%$. In a survey conducted by the United States National Health and Examination (NHANES 3), 4.2\% of 16,534 individuals were diagnosed to have $\mathrm{SCH}$, after excluding patients previously diagnosed to have hypothyroidism and those undergoing treatment for the same.[6] The prevalence was higher among females and whites as compared to males and blacks respectively. In India, a study by Unnikrishnan et al, on 971 adults in Cochin revealed a prevalence of SCH of $9.4 \%$. The prevalence was higher in women as compared to men.[7]

The prevalence of SCH in individuals with type 2 DM is similar to that of the general population. According to the Fremantle Diabetes Study, the prevalence of SCHT was found 
to be $8.7 \%$, and this prevalence was associated with an elevation in the antibodies to thyroid peroxidase and age.[8]

The effect of SCH on the glycaemic profile appears to be controversial. Most of the studies comparing SCH and type 2 DM could not come up with a statistically significant correlation between level of thyroid dysfunction and glycaemic profile. In contrast, the Greek study on type 2 DM patients showed a reduced $\mathrm{HbA}_{1 \mathrm{c}}$ level in patients with coexisting hypothyroidism $(7.38 \%$ compared to $7.81 \%)$ although this was statistically insignificant.[9] The same observation was made by Kim et al in Taiwan, with a mean $\mathrm{HbA}_{1 \mathrm{c}}$ of $8.8 \%$ and $8.4 \%$ in euthyroid and hypothyroid diabetic individuals respectively.[10] The variations in the above observations and the absence of any significant findings is probably due to the multiple mechanisms by which hypothyroidism can decrease as well as increase the blood glucose values.

Hypothyroidism has a definite impact on the lipid profile in individuals with Type 2 DM, although the pattern of lipid profile varies among different studies. In a study in the Greek population, diabetic patients with thyroid disorders had better lipid profile, regarding LDL- and HDL-cholesterol levels, compared with diabetic subjects without thyroid dysfunction. A recent meta-analysis has showed that subclinical hypothyroidism does not seem to be associated with dyslipidaemia.[11] A study by Chubb et al did not find any significant relationship between subclinical hypothyroidism and the presence of dyslipidaemia.[8] However, Kim et al conducted a study on type $2 \mathrm{DM}$ and $\mathrm{SCH}$, and found elevated total and LDL cholesterol among those with SCH compared to euthyroid individuals. ${ }^{[10]}$

The present study was conducted in a tertiary care hospital on 200 patients of type $2 \mathrm{DM}$. The prevalence of SCH was $12 \%$, the prevalence being higher among females. There was no correlation between the age of the individual and prevalence of $\mathrm{SCH}$. $\mathrm{HbA}_{1 \mathrm{c}}$ levels are higher among individuals with $\mathrm{SCH}$, and this was found to be statistically significant. The prevalence and mean values of total and LDL cholesterol were higher in the SCH group than the euthyroid group. Serum triglyceride levels were significantly higher in the SCH group as compared to the euthyroid group.

It is essential to detect individuals with $\mathrm{SCH}$ as they can progress to OHT. The rate of progression to OHT in the general population is $2.6 \%$ per year, the rate being higher ( $4.3 \%$ per year) if the patient has positive antibodies to serum thyroid peroxidase (TPO).[2] There are no stringent guidelines regarding the treatment of SCH. Generally, individuals are considered for treatment if they are positive for anti-TPO antibodies, if they have symptoms of hypothyroidism, or if the TSH levels are grossly elevated (TSH $>10 \mu \mathrm{IU} / \mathrm{mL})^{\left[{ }^{[12]}\right.}$

\section{CONCLUSION}

Subclinical hypothyroidism is prevalent among patients with type $2 \mathrm{DM}$, especially among female patients. Higher $\mathrm{HbA}_{1 \mathrm{c}}$ levels correlate with higher rates of subclinical hypothyroidism. Elevated Total and LDL cholesterol levels are more prevalent among those with SCH but not statistically significant. There is a significantly higher prevalence of hypertriglyceridaemia in patients with both SCH and type 2 DM.

\section{REFERENCES}

[1] Rivolta G, Cerutti R, Colombo R, et al. Prevalence of subclinical hypothyroidism in a population living in the Milan metropolitan area. J Endocrinol Invest 1999;22(9):693-7.

[2] Vanderpump MP, Tunbridge WM, French JM, et al. The incidence of thyroid disorders in the community: a twenty-year follow-up of the Whickham survey. Clin Endocrinol (Oxf) 1995;43(1):55-68.

[3] Perros P, McCrimmon RJ, Shaw G, et al. Frequency of thyroid dysfunction in diabetic patients: value of annual screening. Diabet Med 1995;12(7):622-7.

[4] Chehade JM, Gladysz M, Mooradian AD. Dyslipidemia in type 2 diabetes: prevalence, pathophysiology, and management. Drugs 2013;73(4):327-39.

[5] Pandya H, Lakhani JD, Trivedi A. The Prevalence and pattern of dyslipidemia among type 2 diabetic patients at a rural based hospital in Gujarat, India. Ind J Clin Practice 2012;22(12):36-44.

[6] Hollowell JG, Staehling NW, Flanders WD, et al. Serum TSH, T(4), and thyroid antibodies in the United States population (1988 to 1994): national health and nutrition examination survey (NHANES III). J Clin Endocrinol Metab 2002;87(2):489-99.

[7] Menon UV, Sundaram KR, Unnikrishnan AG, et al. High prevalence of undetected thyroid disorders in an iodine sufficient adult south Indian population. J Indian Med Assoc 2009;107(2):72-7.

[8] Chubb SA, Davis WA, Inman Z, et al. Prevalence and progression of subclinical hypothyroidism in women with type 2 diabetes: the Fremantle diabetes study. Clin Endocrinol (Oxf) 2005;62(4):480-6.

[9] Papazafiropoulou A, Sotiropoulos A, Kokolaki A, et al. Prevalence of thyroid dysfunction among Greek type 2 diabetic patients attending an outpatient clinic. J Clin Med Res 2010;2(2):75-8.

[10] Kim BY, Kim CH, Jung CH, et al. Association between subclinical hypothyroidism and severe diabetic retinopathy in Korean patients with type 2 diabetes. Endocrine Journal 2011;58(12):1065-70.

[11] Hueston WJ, Pearson WS. Subclinical hypothyroidism and the risk of hypercholesterolemia. Ann Fam Med 2004;2(4):351-5.

[12] Garber JR, Cobin RH, Gharib H, et al. Clinical practice guidelines for hypothyroidism in adults: cosponsored by the American association of clinical endocrinologists and the American thyroid association. Thyroid 2012;22(12):1200-35. 